\title{
The Incidence of Retinopathy of Prematurity in a Tertiary Care Center in Turkey
}

\author{
(1) Dilbade Yildiz Ekinci, ${ }^{1}$ (1) Sadik Etka Bayramoglu, ${ }^{2}$ (1) Asli Deger Vural ${ }^{3}$ \\ ${ }^{1}$ Department of Ophthalmology, Gazi Yasargil Training and Research Hospital, Diyarbakir, Turkey \\ ${ }^{2}$ Department of Ophthalmology, Kanuni Sultan Suleyman Training and Research Hospital, Istanbul, Turkey \\ ${ }^{3}$ Department of Ophthalmology, Bakirkoy Sadi Konuk Training and Research Hospital, Istanbul, Turkey
}

\begin{abstract}
Objectives: The objective of our study was to determine the incidence of retinopathy of prematurity (ROP) in our hospital, which gives tertiary health services.

Methods: In this retrospective study, the medical files of the infants, who were born before the 36th gestational age and applied for the examination of ROP between 2014 and 2017 to Istanbul Kanuni Sultan Suleyman Training and Research Hospital, were investigated. The birth weight, gestational age, type of delivery, and the development of ROP were recorded.

Results: The mean gestational age and mean birth weight of 2913 infants, who were screened for ROP, were $32.3 \pm 2.9$ (22-36) weeks and $1846 \pm 580 \mathrm{~g}(360-4300)$, respectively. $48.7 \%$ of the patients were females and $5 \mathrm{I} .3 \%$ were males. $32.4 \%$ of the patients had ROP at any stage. $8.8 \%$ of the infants had severe ROP and were treated accordingly. The mean gestational age and the mean gestational weight of the infants in this group were $28.0 \pm 2.6$ weeks (22-35) and I I7I.9 $\pm 417.5 \mathrm{~g}(360-2500)$, respectively. The mean birth weight was lower in the severe ROP group compared to the group with no ROP development. 28 infants (0.9\%) with birth weight over $2500 \mathrm{~g}(2502-3740)$ had only mild ROP and improved spontaneously.

Conclusion: As it was determined that the mean gestational age and weight were lower in infants with ROP than the infants with no ROP development, so the importance of the low birth weight and the gestational age was confirmed as risk factors for ROP development.
\end{abstract}

Keywords: Gestational age, low birth weight, retinopathy of prematurity, screening results.

\section{Introduction}

Retinopathy of prematurity (ROP) was described by Terry as retrolental fibroplasia in 1942 and defined as a vasoproliferative retina disorder of the premature infants (I). ROP is worldwide the third most common cause of the blindness in childhood (2). In addition, such as cataract and glaucoma, it is also one of the preventable causes of blindness (2). Today, with the help of the screening and monitoring programs, infants under risk can be easily detected, and the blindness can be prevented with proper treatment (3).
In recent years, with the improvement of the neonatal intensive care conditions, infants even with a very early gestational age kept alive (4). However, the increase in the number of the premature infants kept alive, an epidemia of ROP emerged (5). In the developed countries, the rate of blindness related to ROP is less than developing countries thanks to the technological development and presence of sufficient experienced staff (6). In less developed countries, ROP is encountered also in infants with a relatively higher gestational age, and birth weight and the blindness related

Address for correspondence: Dilbade Yıldız Ekinci, MD. Gazi Yasargil Egitim ve Arastirma Hastanesi,

Oftalmoloji Bolumu, Diyarbakir, Turkey

Phone: +90 5053694918 E-mail: dilbadeekinci@gmail.com

Submitted Date: September 12, 2018 Accepted Date: December 18, 2018 Available Online Date: December 27, 2018

${ }^{\circ}$ Copyright 2018 by Beyoglu Eye Training and Research Hospital - Available online at www.beyoglueye.com 
to ROP is much more common (6-9). In a multicenter study conducted in our country, the investigators reported that the rate of ROP at any stage was $30 \%$ and they stated that the ROP incidence was comparable with other developing countries (10).

The objective of our study was to determine the incidence of ROP in premature infants followed up in our hospital, which gives tertiary health-care services in Istanbul, the biggest metropolis of Turkey.

\section{Methods}

This study was conducted in the Istanbul Kanuni Sultan Süleyman Training and Research Hospital with the retrospective screening of the premature infants, who were followed up and treated in the Diagnosis and Treatment Center with the diagnosis of ROP between April 2014 and September 2017. In line with the recommendations of the American Academy of Pediatrics and American Academy of Ophthalmology in 2006, we included in the ROP screening program, the premature infants, who were under the gestational age of 32 weeks and under the birth weight of $1500 \mathrm{~g}$ and the premature infants with a gestational age of 32 weeks and the birth weight over $1500 \mathrm{~g}$ but with risk factors. We obtained informed patient consents from the families of all infants enrolled in the screening program. We recorded the gender, gestational ages, birth weights, types of delivery, and postconceptional ages determined during the examination.

The first ophthalmological examination of the patients was performed between 30 th and $3 \mathrm{I}$ st postmenstrual weeks in infants with a gestational age $<27$ weeks and in the 4th postnatal week in infants with a higher gestational age $(\geq 27$ weeks).

Regarding the examination, after the discontinuation of oral feeding, mydriasis was obtained with the 3 times application of $0.5 \%$ tropicamide (Tropamid, Bilim Illaç, Turkey) and $2.5 \%$ phenylephrine (Mydfirin, Alcon, USA). 30 min following the installation the infant was referred to the examination room, and topical anesthesia was carried out with $0.5 \%$ proparacaine hydrochloride (Alcain, Alcon, USA). Three experienced ophthalmologists examined the infants (DYE, SEB, AV) with a binocular indirect ophthalmoscope and 20 and 28 dioptry lenses (Volk, USA). Following the application of the sterile ophthalmic speculum, the peripheral retina was examined with the scleral depressor. Findings were recorded according to the classification of ROP zone, stage, extent of the disease (II). The examination interval was set according to the presence of the disease, zone, and severity between 2 days and 3 weeks. All patients were followed up until the completion of the retinal vascularization. Infants, who had a high-risk prethreshold disease (Type I ROP) and aggressive posterior ROP (APROP) according to the early treatment for ROP criteria, were treated. The treatment was performed with laser photocoagulation or intravitreal anti-vascular endothelial growth factor (VEGF) within $72 \mathrm{~h}$.

\section{Results}

A total of 2913 infants, who were enrolled in the study, were gestational age lower than 32 weeks and had a birth weight lower than $1500 \mathrm{~g}$ or were gestational age higher than 32 weeks and had a birth weight over $1500 \mathrm{~g}$ birth weight but had risk factors. These infants were hospitalized, screened and followed up for ROP between April 2014 and September 2017. 1419 of the patients (48.7\%) were females and 1494 (51.3\%) were males. The mean gestational age was $32.3 \pm 2.9$ weeks (22-36) and the mean birth weight was $1846 \pm 580 \mathrm{~g}$ (360-4300) (Table I). $18.6 \%$ of the infants were born with normal spontaneous vaginal and $81.4 \%$ with cesarean delivery.

Nearly $67.6 \%$ of the patients $(n=1963)$ did not develop ROP. $14.6 \%$ of the infants had Stage I ROP, 9.3\% Stage 2, 4\% Stage 3 , and $4.5 \%$ had APROP. We did not encounter Stage 4 or 5 ROP at the time of the first diagnosis (Table 2). The mean gestational age and birth weight of infants, who developed ROP, were $30.0 \pm 2.9$ weeks and $1462.2 \pm 5 \mathrm{I} 5$. I g. The mean gestational age and mean birth weight of infants, who did not develop ROP, were $33.4 \pm 2$.I weeks and $2034.0 \pm 5$ I4.6 g. According to these results, the mean gestational age and birth weight of infants with ROP were significantly lower than the infants without ROP $(p<0.000)$. The mean gestational age of the ROP diagnosis was $37.0 \pm 2.4$ weeks $(30-46)$. In patients with mild-to-moderate ROP, who did not need treatment, the disease regressed on average at the 43.8 55.0 (35-65) premenstrual weeks (PMW). Besides the treated infants, the retinal vascularization was completed at $44.3 \pm 4.4(40-73)$ PMW. There were no unfavorable outcomes such as retinal detachment, macular ectopia, and optic disc dragging among the followed up patients (Table 3 ).

Severe ROP diagnosed in $8.8 \%$ of the patients $(n=257)$ and all of these patients eyes were treated. In $42.2 \%$ of the 257 patients, who were diagnosed with severe ROP and treated accordingly, the disease was in Zone I and 57.8\% in Zone 2. Laser photocoagulation or intravitreal anti-VEGF treatment was carried out within $24 \mathrm{~h}$ in infants, who were diagnosed with Type I ROP or APROP. We did not encounter any complication related to the administered treatments.

Nearly $77.1 \%$ of the infants with a gestational age below 28 had ROP at any stage. This rate was $13.1 \%$ in infants with gestational weeks (GW) over 32. The rate of the infants, who were below $28 \mathrm{GW}$ and treated due to the severe ROP, was $38 \%$ and the rate of the infants, who were higher than $32 \mathrm{GW}$ and treated, was $0.9 \%(n=14)$. There were only 9 infants $(0.3 \%)$ with a birth weight between $2000 \mathrm{~g}$ and 2500 $\mathrm{g}$, who underwent treatment. We detected mild ROP in 28 
Table I. The average gestational age and birth weight

\begin{tabular}{lcccc} 
& n & Minimum & Maximum & Mean \pm SD \\
\hline Gestational age & 2913 & 22.00 & 36.00 & $32.3134 \pm 2.92117$ \\
Birth weight & 2913 & 360.00 & 4300.00 & $1846.9949 \pm 580.42741$ \\
\hline
\end{tabular}

SD: Standard deviation.

Table 2. The distribution of ROP in the eyes

\begin{tabular}{lccc} 
ROP & Frequency (\%) & Valid percent & Cumulative percent \\
\hline Valid & & & 67.5 \\
Stage 0 & $3935(67.5)$ & 67.5 & 82.1 \\
Stage I & $851(14.6)$ & 14.6 & 91.5 \\
Stage 2 & $544(9.3)$ & 9.3 & 95.5 \\
Stage 3 & $234(4.0)$ & 4.0 & 100.0 \\
APROP & $262(4.5)$ & 4.5 & \\
Total & $5826(100.0)$ & 100.0 & \\
\hline
\end{tabular}

ROP: Retinopathy of prematurity.

Table 3. The distribution of treated and untreated eyes

\begin{tabular}{lccc} 
& Frequency (\%) & Valid percent & Cumulative percent \\
\hline Valid & & & 91.2 \\
Untreated eyes & $5312(91.2)$ & 91.2 & 100.0 \\
Treated eyes & $514(8.8)$ & 8.8 & \\
Total & $5826(100.0)$ & 100.0 & \\
\hline
\end{tabular}

infants $(0.9 \%)$ with birth weight over $2500 \mathrm{~g}(2502-3740)$. The disease regressed spontaneously in all these infants during the follow-up.

\section{Statistical Analysis}

SPSS (SPSS Inc, PASW Statistics for Windows, Version, 18.0, Chicago, USA) software package was used for the statistical analysis. The normal distribution of the data was evaluated with the Kolmogorov-Smirnov test. Normally, distributed parameters were compared with the "Independent t-test." For the comparison of the parameters, which did not show a normal distribution, we used "Mann-Whitney U-test".

\section{Discussion}

Although most of the risk factors of ROP are known today, it is still not a preventable disease. The blindness rate related to ROP is under $10 \%$ in the developed countries but can increase up to $40 \%$ in the developing countries, where it affects also infants with relatively higher birth weight and $\operatorname{GW}(3,8,9)$. American Academies of Pediatrics and Ophthalmology recommended that infants with a birth weight of $\leq 1500 \mathrm{~g}$ or ges- tational age of 30 weeks or less and infants with birth weight between $1500 \mathrm{~g}$ and $2000 \mathrm{~g}$ or gestational age of $>30$ weeks with an unstable clinical course, should be screened for ROP (12). However, studies have shown that these screening criteria might be insufficient for the prevention of blindness related to ROP in developing countries $(10,13,14)$.

In our study, we detected ROP at any stage in $32.4 \%$ of the screened infants. In a multicenter study conducted in our country, it was found out that the incidence of ROP was $30 \%$ (10). The incidence of ROP is $17.9 \%$ in the USA, between $19 \%$ and $46 \%$ in India and $31.3 \%$ in Portugal (15-18). According to our results, ROP is a serious problem that may cause potentially blindness for premature babies unless the neonatal intensive care services would be eligible conditions. However, in spite of the high incidence of ROP, the absence of Stage 4 or 5 ROP, which have a poor prognosis at the time of the first diagnosis, shows that an intensive ROP screening program is implemented in our country to reduce the number of blindness related to ROP.

The incidence of severe ROP is $8.31 \%$ in the USA, $5 \%$ 
in Turkey and between $4 \%$ and $9 \%$ in India $(10,15-17)$. We considered treatment in $8.8 \%$ of the screened infants due to the severe ROP. In light of these data, we noticed that our incidence of severe ROP was comparable with the USA, although the overall incidence of ROP is relatively higher. The finding of the increased incidence of ROP, which should be treated, compared to the data from 2013, may be explained with that our hospital which gives service to the most crowded region of Turkey; the cases, who need treatment, are referred to our hospital from other ROP diagnosis centers in our region, and the ROP incidence increased especially due to the reduced mortality in infants with a lower gestational age.

The incidence of ROP was $77.1 \%$ among the infants with a gestational age lower than 28 weeks and $38 \%$ of them had severe ROP. In a Swedish study, the incidences of ROP and severe ROP were $72.7 \%$ and $34.8 \%$, respectively (19). The same incidences were $64.7 \%$ and $1 \mathrm{I} .6 \%$ in the study of Isaza and Arora; $60.7 \%$ and $16.2 \%$ in a Chinese study, respectively $(20,21)$. According to our findings, the incidences of ROP and severe ROP in the patient group with a gestational age lower than $\mathbf{2 8}$ are higher than in other countries. Although the mortality rate of the infants with a very low gestational age is gradually declining, the incidence of ROP, which causes severe ocular morbidity, continues to be still at a high level.

The evaluation of infants with a gestational age higher than 32 showed that the incidences of ROP and severe ROP were $13.1 \%$ and $0.9 \%$, respectively. Only 4 infants with a gestational age over 34 weeks had ROP, which needed treatment. The incidence of severe ROP was $0.3 \%$ in infants with birth weight over $2000 \mathrm{~g}$. In the USA, it was demonstrated that the incidence of ROP was $1.9 \%$ in infants with a gestational age higher than 32 weeks and $2.4 \%$ in infants with birthweight over $2500 \mathrm{~g}$. Two separate studies in Turkey, one conducted in the Western Black Sea region and the other in a health center with one of the biggest neonatal intensive care unit, it was shown that no ROP requiring treatment was detected in infants with a gestational age higher than 32 weeks, and it was recommended that the ROP screening should be focused on infants with a gestational age lower than 32 weeks and a birth weight under $1500 \mathrm{~g}(22,23)$. In our study, we detected severe ROP in infants with higher birth weight and gestational age compared to these studies conducted in two separate intensive care units in our country. Our ROP diagnosis treatment center provides screening and treatment service to the intensive care units of other private and state hospitals, besides our intensive care unit. Conflicting results in the same country shows that the neonatal care is still not standardized in our country and ROP will be encountered only in smaller premature infants like in developed countries if the conditions of the intensive care units will be improved. In addition, our findings show the importance of the improvement of the neonatal intensive care regarding staff and technological equipment, supervision of the service quality and development of intensive health strategies against ROP, which causes serious rates of mortality.

All infants with a gestational age lower than 36 weeks, who were hospitalized in intensive care units due to various reasons (asphyxia, meconium aspiration, and sepsis ... ), should be considered as high-risk infants by neonatologists regardless of the birth weight and should be referred for a ROP examination. ROP was detected in 28 infants with birth weight over $2500 \mathrm{~g}$, and some of them had a birth weight over $3000 \mathrm{~g}$. The presence of the ROP - even mild - in infants with very high birth weight may indicate that these infants received uncontrolled oxygen treatment and received insufficient care. However, as the epicirisis of these patients were not available, the related risk factors could not be evaluated. In our study, the presence of the ROP in infants with birth weight over $2500 \mathrm{~g}$ indicates that all infants, who were referred by neonatologists for the ROP examination, should be examined regardless of the birth weight.

In our study, we were not able to access the detailed epicrisis fulfilled during the hospitalization in intensive care units. Therefore, we were not able to evaluate the infants regarding the risk of ROP development. This is the most important limitation of our study. The lower mean gestational age and birth weight in infants with ROP compared to the infants without ROP confirm that low birth weight and gestational age are important risk factors for ROP development. The detected incidence of ROP and severe ROP was high like in other developing countries. In addition, the presence of ROP in infants with higher gestational age and birth weight emphasizes once again the importance of the necessity of the improvement in the neonatal intensive care unit conditions in our country.

\section{Disclosures}

Peer-review: Externally peer-reviewed.

Conflict of Interest: None declared.

Authorship Contributions: Involved in design and conduct of the study (DYE, SEB, ADV); preparation and review of the study (DYE); data collection (DYE); and statistical analysis (SEB).

\section{References}

I. Terry TL. Fibroblastic overgrowth of persistent Tunica vasculosa lentis in infants born prematurely: II. Report of cases-clinical aspects. Trans Am Ophthalmol Soc 1942;40:262-84.

2. Kong L, Fry M, Al-Samarraie M, Gilbert C, Steinkuller PG. An update on progress and the changing epidemiology of causes of childhood blindness worldwide. J AAPOS 2012;16:50I-7.

3. Good WV, Early Treatment for Retinopathy of Prematurity 
Cooperative Group. Final results of the early treatment for retinopathy of prematurity (ETROP) randomized trial. Trans Am Ophthalmol Soc 2004; 102:233-48.

4. Emsley HC, Wardle SP, Sims DG, Chiswick ML, D’Souza SW. Increased survival and deteriorating developmental outcome in 23 to 25 week old gestation infants, 1990-4 compared with 1984-9. Arch Dis Child Fetal Neonatal Ed 1998;78:F99-104.

5. Quinn GE. Retinopathy of prematurity blindness worldwide: Phenotypes in the third epidemic. Eye Brain 2016;8:3I-6.

6. Gilbert C, Fielder A, Gordillo L, Quinn G, Semiglia R, Visintin $P$, et al. Characteristics of infants with severe retinopathy of prematurity in countries with low, moderate, and high levels of development: Implications for screening programs. Pediatrics 2005; II 5:e5 I8-25.

7. Onyango O, Sitati S, Amolo L, Murila F, Wariua S, Nyamu G, et al. Retinopathy of prematurity in Kenya: Prevalence and risk factors in a hospital with advanced neonatal care. Pan Afr Med J 2018;29:152.

8. Zin A, Gole GA. Retinopathy of prematurity-incidence today. Clin Perinatol 2013;40:185-200.

9. Zin AA, Magluta C, Pinto MF, Entringer AP, Mendes-Gomes MA, Moreira ME, et al. Retinopathy of prematurity screening and treatment cost in Brazil. Rev Panam Salud Publica 20I4;36:37-43.

10. Bas AY, Koc E, Dilmen U, ROP Neonatal Study Group. Incidence and severity of retinopathy of prematurity in Turkey. $\mathrm{Br} J$ Ophthalmol 2015;99:1311-4.

I I. International Committee for the Classification of Retinopathy of Prematurity. The international classification of retinopathy of prematurity revisited. Arch Ophthalmol 2005;123:99I-9.

12. Fierson WM. American Academy of Pediatrics Section on Ophthalmology, American Academy of Ophthalmology, AmericanAssociation for Pediatric Ophthalmology and Strabismus, Ameri-can Association of Certified Orthoptists. Screening examination of premature infants for retinopathy of prematurity. Pediatrics 2013;131:189-95.

13. Gutierreza M, Olguín-Manríquezb FJ, Arriola-Lopezb AE, O'Hare JP, Raymond NT. Evidence to modify guidelines for routine retinopathy of prematurity screening to avoid childhood blindness in middle-income countries. Rev Mex Oftalmol 2016;90:167-73.

14. Xu Y, Zhou X, Zhang Q, Ji X, Zhang Q, Zhu J, et al. Screening for retinopathy of prematurity in China: A neonatal units-based prospective study. Invest Ophthalmol Vis Sci 20I3;54:8229-36.

15. Ludwig CA, Chen TA, Hernandez-Boussard T, Moshfeghi AA, Moshfeghi DM. The epidemiology of retinopathy of prematurity in the United States. Ophthalmic Surg Lasers Imaging Retina 2017;48:553-62.

16. Singh K, Gupta S, Jain S, Karnawat BS, Sharma S, Nimel M. To study the incidence of retinopathy of prematurity in high-risk neonates and the risk factors associated with the disease. Indian J Child Health 2017;4:575-9.

17. Rekha S, Battu RR. Retinopathy of prematurity: Incidence and risk factors. Indian Pediatr 1996;33:999-1003.

18. Coutinho I, Pedropa C, Mota M Azeredo-Lopes S, Santos C, Pires G, et al. Retinopathy of prematurity: Results from 10 years in a single neonatal intensive care unit. J Pediatr Neonatal Individ Med 2017;6:60122.

19. Austeng D, Källen KB, Ewald UW, Jakobsson PG, Holmström GE. Incidence of retinopathy of prematurity in infants born before 27 weeks' gestation in Sweden. Arch Ophthalmol 2009;|27:13|5-9.

20. Isaza G, Arora S. Incidence and severity of retinopathy of prematurity in extremely premature infants. Can J Ophthalmol 2012;47:296-300.

21. Yau GS, Lee JW, Tam VT, Liu CC, Wong IY. Risk factors for retinopathy of prematurity in extremely preterm Chinese infants. Medicine (Baltimore) 2014;93:e3।4.

22. Alpay A, Uğurbaş SH. Incidence and risk factors for retinopathy of prematurity in the west black sea region, Turkey. Turk J Pediatr 2012;54:113-8.

23. Sarikabadayi YU, Aydemir O, Ozen ZT, Aydemir C, Tok L, Oguz SS, et al. Screening for retinopathy of prematurity in a large tertiary neonatal intensive care unit in Turkey: Frequency and risk factors. Ophthalmic Epidemiol 20I I; 18:269-74. 